\title{
Hubungan Perilaku Ibu Hamil dengan Kebersihan Gigi dan Mulut (OHI-S) Masa Kehamilan di Puskesmas Pandanwangi Malang
}

The Relationship Between Behavior of Pregnant Women and Oral Hygiene (OHI-S) During Pregnancy in Pandanwangi Health Centre Malang

\author{
Ditta Ika Pra Setya Wati, Anggani Prasasti, Trining Widodorini \\ Program Studi Pendidikan Dokter Gigi, Fakultas Kedokteran Gigi Universitas Brawijaya \\ Jl. Veteran Malang 65145 \\ E-mail: dittaika@gmail.com
}

\begin{abstract}
ABSTRAK
Perilaku ibu hamil didefinisikan sebagai suatu kegiatan atau aktivitas selama masa kehamilan. Dalam penelitian ini perilaku terdiri dari pengetahuan, sikap dan tindakan. Pada masa kehamilan terjadi beberapa perubahan pada bagian tubuh termasuk gigi dan mulut. Salah satu penyebab gangguan kesehatan gigi dan mulut adalah ada atau tidaknya faktor lokal (debris dan calculus). Kebersihan gigi dan mulut diukur dengan menggunakan Oral Hygiene Index-Simplified (OHI-S). Tujuan: untuk membuktikan adanya hubungan perilaku ibu hamil dengan kebersihan gigi dan mulut (OHI-S) selama masa kehamilan. Metode: consecutive sampling dilakukan pada ibu hamil yang berkunjung ke Puskesmas Pandanwangi Kota Malang dan memenuhi kriteria pada bulan Agustus sampai bulan September selama 30 hari dengan pendekatan cross sectional, sehingga didapatkan sampel sebanyak 50 ibu hamil. Hasil: uji korelasi Rank Spearman menunjukkan adanya hubungan signifikan antara pengetahuan ibu hamil dengan $O H I-S$ dengan korelasi $r=-0.711$, adanya hubungan signifikan antara sikap ibu hamil dengan $O H I-S$ dengan korelasi $r=-0.707$, serta adanya hubungan signifikan antara tindakan ibu hamil dengan $O H I-S$ dengan korelasi $r=-0.525$. Kesimpulan: terdapat hubungan perilaku ibu hamil dengan kebersihan gigi dan mulut (OHI-S) selama masa kehamilan di Puskesmas Pandanwangi Kota Malang.
\end{abstract}

Kata Kunci: Perilaku Ibu Hamil, Pengetahuan, Sikap, Tindakan, OHI-S 


\begin{abstract}
Behavior of pregnant women is defined as an activity or activity during pregnancy. In this study the behavior consists of knowledge, attitudes and actions. During pregnancy there are some changes on the part of the body including the teeth and mouth. One of the causes of dental and oral health problems is the presence or absence of local factors (debris and calculus). Dental and oral hygiene was measured using the Simplified Oral-Hygiene Index (OHI-S). Purpose: to prove a link behavior of pregnant women with dental and oral hygiene (OHI-S) during pregnancy. Methods: Consecutive sampling performed on pregnant women who visited the health center Pandanwangi Malang and meet the criteria in August to September for 30 days with a cross sectional approach, so we get a sample of 50 pregnant women. Results: Spearman Rank correlation test showed a significant correlation between the knowledge of pregnant women with OHI-S with a correlation of $r=-0711$, the existence of a significant relationship between the attitude of pregnant women with OHI-S with a correlation of $r=-0707$, as well as the existence of a significant association between maternal action pregnant with OHI-S with a correlation of $r=-0525$. Conclusion: there is a relationship behavior of pregnant women with dental and oral hygiene (OHI-S) during pregnancy in Puskesmas Pandanwangi Malang.
\end{abstract}

Keywords: Maternal Behavior, Knowledge, Attitudes, Actions, OHI-S 


\section{PENDAHULUAN}

Perilaku ibu hamil didefinisikan sebagai suatu kegiatan atau aktivitas selama masa kehamilan. Perilaku ini meliputi pengetahuan, sikap dan tindakan. Beberapa penelitian menyatakan bahwa tingkat pengetahuan, sikap dan tindakan ibu hamil dapat mempengaruhi tingkat kesehatan gigi dan mulut. ${ }^{1,2}$ Kehamilan merupakan suatu proses alamiah yang melibatkan beberapa perubahan pada bagian tubuh, termasuk gigi dan mulut. Perubahan tersebut meliputi perubahan anatomi, fisiologi dan psikologi., ${ }^{3,4}$

Pemeliharaan kesehatan gigi dan mulut dapat dilakukan salah satunya dengan menjaga kebersihan gigi dan mulut. Saat ini lebih banyak perhatian ditujukan pada kebersihan gigi dan mulut ibu hamil karena adanya hubungan antara kehamilan, kesehatan, dengan kebersihan gigi dan mulut. ${ }^{5}$ Kesadaran wanita hamil akan pentingnya menjaga kebersihan gigi dan mulut untuk memelihara kesehatannya sangat penting. Perilaku yang meliputi pengetahuan, sikap dan tindakan ibu hamil terhadap kebersihan gigi dan mulut juga menentukan status kebersihan rongga mulutnya. Hal ini dikarenakan kebersihan gigi dan mulut dapat menentukan besar kecilnya risiko terserang penyakit gigi dan mulut.

Pada penelitian ini kebersihan gigi dan mulut diukur berdasarkan Oral Hygiene IndexSimplified (OHI-S) yang ditemukan oleh Greene dan Vermillion. ${ }^{6}$ Melalui pengukuran ini akan diketahui derajat kebersihan gigi dan mulut yang dihubungkan dengan $O H I-S$. Melalui pemeriksaan ini akan didapatkan ada atau tidaknya faktor lokal di dalam rongga mulut. Faktor lokal merupakan faktor penentu terjadinya gangguan kesehatan gigi dan mulut selama memicu terjadinya gangguan kesehatan rongga mulutnya, maka penulis tertarik untuk melakukan penelitian mengenai hubungan perilaku ibu hamil (yang meliputi pengetahuan, sikap dan tindakan) dengan kebersihan gigi dan mulut selama masa kehamilan. Masa kehamilan yang diperparah oleh adanya perubahan hormonal.

Kurangnya kesadaran ibu hamil untuk menjaga kebersihan gigi dan mulut yang dapat Penelitian ini dilakukan di Puskesmas Pandanwangi Kota Malang karena menurut data yang diperoleh dari Dinas Kesehatan Kota Malang, Puskesmas Pandanwangi merupakan Puskesmas yang memiliki kunjungan ibu hamil dengan rata-rata terbanyak dari tahun 2008 sampai 2010. Hasil penelitian ini diharapkan dapat memberikan informasi dan pengetahuan pada ibu hamil akan pentingnya menjaga kebersihan gigi dan mulut pada masa kehamilan untuk mencegah terjadinya gangguan kesehatan gigi dan mulutnya.

Tujuan dari penelitian ini adalah untuk mempelajari hubungan perilaku ibu hamil yang meliputi pengetahuan, sikap dan tindakan dengan kebersihan gigi dan mulut (OHI-S) selama masa kehamilan di Puskesmas Pandanwangi Kota Malang.

\section{METODE PENELITIAN}


Jenis rancangan penelititan ini adalah penelitian survei analitik dengan pendekatan cross sectional. ${ }^{7}$ Cara pengambilan sampel pada penelitian ini menggunakan teknik non probability sampling dengan metode consecutive sampling, ${ }^{8}$ yaitu ibu hamil yang berkunjung ke Puskesmas Pandanwangi Kota Malang setiap hari Senin sampai dengan Sabtu pada jam kerja pukul 08.00-12.00 WIB pada bulan Agustus sampai dengan bulan September tahun 2011 selama 30 hari dan memenuhi kriteria sebagai sampel penelitian. Ibu hamil yang bersedia menjadi responden harus mengisi dan menandatangani informed consent untuk menghindari hal-hal yang tidak diinginkan. Dalam penelitian ini yang diukur adalah perilaku ibu hamil (yang meliputi pengetahuan, sikap dan tindakan) menggunakan kuesioner yang dikombinasikan dengan teknik wawancara untuk menghindari kelemahan kuesioner dan wawancara itu sendiri yang dilakukan oleh peneliti, serta kebersihan gigi dan mulut berdasarkan Oral Hygiene IndexSimplified (OHI-S) yang dilakukan oleh dokter gigi Puskesmas setempat sehingga dalam penelitian ini peneliti hanya bertindak sebagai pengamat dan pencacat hasil pemeriksaan. Kuesioner yang digunakan telah memenuhi persyaratan validitas dan reliabilitas pada uji pendahuluan. Kemudian dilakukan analisis untuk mencari ada atau tidaknya hubungan perilaku ibu hamil dengan kebersihan gigi dan mulut selama masa kehamilan. Penelitian ini dilaksanakan di Puskesmas Pandanwangi Kota Malang jalan Laksamana Adi Sucipto No 315 pada bulan Agustus sampai dengan bulan September 2011 selama 30 hari.

\section{HASIL PENELITIAN}

Jumlah responden sebanyak 50 ibu hamil yang berkunjung di Puskesmas Pandanwangi Kota Malang dan memenuhi kriteria sebagai sampel penelitian. Karakteristik responden yang diperoleh dari hasil penelitian ini adalah usia, pendidikan, pekerjaan, dan paritas (pengalaman).

Perilaku ibu hamil diukur berdasarkan tingkat pengetahuan, sikap dan tindakan serta kebersihan gigi dan mulut diukur berdasarkan Oral Hygiene Index-Simplified (OHI-S), sebagai berikut:

Tabel 1. Distribusi Frekuensi Responden Berdasarkan Pengetahuan

\begin{tabular}{ccc}
\hline KRITERIA & FREKUENSI $(\mathrm{f})$ & PROSENTASE $(\%)$ \\
\hline Tinggi & 12 & 24 \\
\hline Sedang & 30 & 60 \\
\hline Rendah & 8 & 16 \\
\hline Total & 50 & 100 \\
\hline
\end{tabular}


Tabel 2. Distribusi Frekuensi Responden Berdasarkan Sikap

\begin{tabular}{ccc}
\hline KRITERIA & FREKUENSI (f) & PROSENTASE (\%) \\
\hline Baik & 12 & 24 \\
\hline Sedang & 32 & 64 \\
\hline Buruk & 6 & 12 \\
\hline Total & 50 & 100 \\
\hline
\end{tabular}

Sumber: Data Primer, 2011

Tabel 3. Distribusi Frekuensi Responden Berdasarkan Tindakan

\begin{tabular}{ccc}
\hline KRITERIA & FREKUENSI $(\mathrm{f})$ & PROSENTASE $(\%)$ \\
\hline Baik & 11 & 22 \\
\hline Sedang & 34 & 68 \\
\hline Buruk & 5 & 10 \\
\hline Total & 50 & 100
\end{tabular}

Sumber: Data Primer, 2011

Tabel 4. Distribusi Frekuensi Responden Berdasarkan OHI-S

\begin{tabular}{ccc}
\hline KRITERIA & FREKUENSI $(\mathrm{f})$ & PROSENTASE $(\%)$ \\
\hline Baik & 7 & 14 \\
\hline Sedang & 33 & 66 \\
\hline Buruk & 10 & 20 \\
\hline Total & 50 & 100
\end{tabular}

Sumber: Data Primer, 2011

Dari Tabel 1, terlihat bahwa sebagian besar responden yang berkunjung ke Puskesmas Pandanwangi mempunyai tingkat pengetahuan sedang (skor total: 20,33-29,67) yaitu sebanyak 30 responden $(60 \%)$.

Dari Tabel 2, dapat diketahui bahwa sebagian besar sikap responden di Puskesmas Pandanwangi selama masa kehamilan adalah sedang (skor total: 20,33-29,67), yaitu sebanyak 32 responden (64\%).

Dari Tabel 3, terlihat bahwa sebagian besar tindakan responden selama masa kehamilan di Puskesmas Pandanwangi adalah sedang (skor total: 12-16), yaitu sebanyak 34 responden $(68 \%)$.

Tabel 5. Hubungan Pengetahuan Ibu Hamil dengan Kebersihan Gigi dan Mulut (OHI-S) Selama Masa Kehamilan

$$
\text { Skor }
$$

Dari Tabel 4, dapat diketahui bahwa sebagian besar tingkat kebersihan gigi dan mulut responden selama masa kehamilan adalah sedang (skor total menurut Greene dan Vermillion: $1,3-3,0)$, yaitu sebanyak 33 responden (66\%).

Selanjutnya pada penelitian ini analisis yang digunakan untuk menguji hubungan antar variabel adalah uji korelasi Rank Spearman dan semua perangkat analisis statistik menggunakan fasilitas SPSS 17.0 dari Windows. 


\begin{tabular}{|c|c|c|c|c|c|c|c|c|c|c|}
\hline \multirow[t]{2}{*}{ OHI-S } & \multicolumn{2}{|c|}{ Tinggi } & \multicolumn{2}{|c|}{ Sedang } & \multicolumn{2}{|c|}{ Rendah } & \multicolumn{2}{|c|}{ TOTAL } & \multirow[t]{2}{*}{ Signifikansi } & \multirow[t]{2}{*}{ Korelasi (r) } \\
\hline & $n$ & $\%$ & $n$ & $\%$ & $\mathrm{n}$ & $\%$ & $\mathrm{n}$ & $\%$ & & \\
\hline Baik & 7 & 58.33 & 0 & 0 & 0 & 0 & 7 & 14 & & \\
\hline Sedang & 5 & 41.67 & 28 & 93.33 & 0 & 0 & 33 & 66 & 0,000 & -0.711 \\
\hline Buruk & 0 & 0 & 2 & 6.67 & 8 & 100 & 10 & 20 & & \\
\hline TOTAL & 12 & 100 & 30 & 100 & 8 & 100 & 50 & 100 & & \\
\hline
\end{tabular}

Sumber: Data Primer, 2011

Berdasarkan Tabel 5. Kemudian dicari hubungan antara pengetahuan ibu hamil dengan kebersihan gigi dan mulut (OHI-S) selama masa kehamilan di Puskesmas Pandanwangi Kota Malang dengan menggunakan uji korelasi Rank Spearman. Diperoleh nilai koefisien korelasi sebesar $r=-$ 0.711 , artinya bahwa hubungan yang terjadi adalah hubungan yang berlawanan arah, yaitu semakin besar skor pengetahuan maka semakin kecil skor OHI-S dan sebaliknya.
Semakin besar skor pengetahuan artinya semakin tinggi tingkat pengetahuan ibu hamil, tetapi semakin kecil skor OHI-S artinya semakin baik tingkat kebersihan gigi dan mulut ibu hamil. Nilai korelasi Rank Spearman ini mempunyai nilai Signifikansi $=0.000$ kurang dari taraf signifikan $a=0.05$, sehingga dapat disimpulkan bahwa terdapat hubungan yang signifikan antara pengetahuan ibu hamil dengan kebersihan gigi dan mulut (OHI-S) selama masa kehamilan.

Tabel 6. Hubungan Sikap Ibu Hamil dengan Kebersihan Gigi dan Mulut (OHI-S) Selama Masa Kehamilan

\begin{tabular}{|c|c|c|c|c|c|c|c|c|c|c|}
\hline Skor & \multicolumn{8}{|c|}{ Sikap } & \multicolumn{2}{|c|}{ Uji Korelasi } \\
\hline OHI-S & \multicolumn{2}{|c|}{ Baik } & \multicolumn{2}{|c|}{ Sedang } & \multicolumn{2}{|c|}{ Buruk } & \multicolumn{2}{|c|}{ TOTAL } & Signifikansi & Korelasi (r) \\
\hline & $\mathrm{n}$ & $\%$ & $\mathrm{n}$ & $\%$ & $\mathrm{~N}$ & $\%$ & $\mathrm{~N}$ & $\%$ & & \\
\hline Baik & 7 & 58.33 & 0 & 0 & 0 & 0 & 7 & 14 & & \\
\hline Sedang & 5 & 41.67 & 28 & 87.5 & 0 & 0 & 33 & 66 & 0,000 & -0.707 \\
\hline Buruk & 0 & 0 & 4 & 12.5 & 6 & 100 & 10 & 20 & & \\
\hline TOTAL & 12 & 100 & 32 & 100 & 6 & 100 & 50 & 100 & & \\
\hline
\end{tabular}

Sumber: Data Primer, 2011

Berdasarkan Tabel 6. kemudian dicari hubungan antara sikap ibu hamil dengan kebersihan gigi dan mulut (OHI-S) selama masa kehamilan di Puskesmas Pandanwangi Kota Malang dengan menggunakan uji korelasi Rank Spearman. Diperoleh nilai koefisien korelasi sebesar $r=-0.707$, artinya bahwa hubungan yang terjadi adalah hubungan yang berlawanan arah, yaitu semakin besar skor sikap maka semakin kecil skor OHI-S dan sebaliknya. Semakin besar skor sikap artinya semakin baik sikap ibu hamil, tetapi semakin kecil skor OHI-S artinya semakin baik tingkat kebersihan gigi 
dan mulut ibu hamil. Nilai korelasi Rank Spearman ini mempunyai nilai Signifikansi $=$ 0.000 kurang dari taraf signifikan $a=0.05$, sehingga dapat disimpulkan bahwa terdapat hubungan yang signifikan antara sikap ibu hamil dengan kebersihan gigi dan mulut (OHI-

S) selama masa kehamilan.

Tabel 7. Hubungan Tindakan Ibu Hamil dengan Kebersihan Gigi dan Mulut (OHI-S) Selama Masa Kehamilan

\begin{tabular}{|c|c|c|c|c|c|c|c|c|c|c|}
\hline Skor & \multicolumn{8}{|c|}{ Tindakan } & \multicolumn{2}{|c|}{ Uji Korelasi } \\
\hline OHI-S & \multicolumn{2}{|c|}{ Baik } & \multicolumn{2}{|c|}{ Sedang } & \multicolumn{2}{|c|}{ Buruk } & \multicolumn{2}{|c|}{ TOTAL } & Signifikansi & Korelasi (r) \\
\hline & $\mathrm{N}$ & $\%$ & $n$ & $\%$ & $\mathrm{~N}$ & $\%$ & $\mathrm{n}$ & $\%$ & & \\
\hline Baik & 7 & 63.64 & 0 & 0 & 0 & 0 & 7 & 14 & & \\
\hline Sedang & 4 & 36.36 & 29 & 85.3 & 0 & 0 & 33 & 66 & 0,000 & -0.525 \\
\hline Buruk & 0 & 0 & 5 & 14.7 & 5 & 100 & 10 & 20 & & \\
\hline TOTAL & 11 & 100 & 34 & 100 & 5 & 100 & 50 & 100 & & \\
\hline
\end{tabular}

Sumber: Data Primer, 2011

Berdasarkan Tabel 7. kemudian dicari hubungan antara tindakan ibu hamil dengan kebersihan gigi dan mulut (OHI-S) selama masa kehamilan di Puskesmas Pandanwangi Kota Malang dengan menggunakan uji korelasi Rank Spearman. Diperoleh nilai koefisien korelasi sebesar $r=-0.525$, artinya bahwa hubungan yang terjadi adalah hubungan yang berlawanan arah, yaitu semakin besar skor tindakan maka semakin kecil skor OHI-S dan sebaliknya. Semakin besar skor tindakan artinya semakin baik tindakan ibu hamil, tetapi semakin kecil skor $O H I-S$ artinya semakin baik tingkat kebersihan gigi dan mulut ibu hamil. Nilai korelasi Rank Spearman ini mempunyai nilai Signifikansi $=$ 0.000 kurang dari taraf signifikan $a=0.05$, sehingga dapat disimpulkan bahwa terdapat hubungan yang signifikan antara sikap ibu hamil dengan kebersihan gigi dan mulut (OHIS) selama masa kehamilan.

\section{PEMBAHASAN}

Perilaku responden dalam penelitian ini terdiri dari pengetahuan responden, sikap responden dan tindakan responden selama masa kehamilanya. Pengetahuan responden yang berkunjung ke Puskesmas Pandanwangi hanya $24 \%$ yang mempunyai tingkat pengetahuan tinggi. Pengetahuan dapat membentuk keyakinan tertentu sehingga seseorang berperilaku sesuai dengan keyakinan tersebut. ${ }^{9}$ Faktor predisposisi seperti pendidikan, pekerjaan, pengalaman dan faktor lainya juga 
turut berperan dalam menentukan tingkat pengetahuan seseorang. ${ }^{2}$

Sikap responden yang berkunjung ke Puskesmas Pandanwangi juga hanya 24\% yang mempunyai sikap baik mengenai kesehatan gigi dan mulut selama kehamilan. Masih kurangnya sikap ibu dapat dipengaruhi oleh pengetahuan dan keyakinan yang dimiliki. Hal ini sesuai dengan Notoatmodjo, mengatakan dalam menentukan sikap yang utuh, pengetahuan, pikiran, keyakinan dan emosi memegang peranan penting. Jadi untuk mendapatkan sikap yang baik diperlukan pengetahuan yang baik juga karena sikap nantinya akan mempengaruhi perilaku seseorang. ${ }^{2}$

Tindakan responden yang berkunjung ke Puskesmas Pandanwangi hanya 22\% mempunyai tindakan baik terhadap kesehatan gigi dan mulut. Untuk terciptanya sebuah tindakan kesehatan selain dipengaruhi oleh pengetahuan dan sikap juga diperlukan faktor pendukung, salah satunya adalah ketersediaan sarana dan prasarana kesehatan. ${ }^{9}$

Pemeriksaan kebersihan gigi dan mulut responden menggunakan Oral Hygine IndexSimplified (OHI-S), dimana hanya 14\% responden yang mempunyai tingkat kebersihan gigi dan mulut baik, selebihnya sedang dan buruk. Tingkat kebersihan gigi dan mulut juga dipengaruhi oleh cara pembersihannya yang benar serta frekuensi kontrol ke dokter gigi. Selain itu juga dapat dipengaruhi oleh jenis makanan yang dikonsumsi sebelum dilakukan pemeriksaan dan usia kehamilan yang rentan akan keluhan mual dan muntah, sehingga mengakibatkan ibu hamil malas membersihkan giginya. Keadaan seperti ini biasanya pada usia kehamilan trimester I.

Hubungan antara pengetahuan ibu hamil dengan kebersihan gigi dan mulut (OHI-S) selama masa kehamilan berdasarkan uji korelasi Rank Spearman, mempunyai nilai Signifikansi $=0.000$ kurang dari taraf signifikan $\mathrm{a}=0.05$ yang menunjukkan bahwa $\mathrm{H}_{0}$ ditolak, sehingga hipotesis dalam penelitian ini dapat diterima. Koefisien korelasi hubungan antara pengetahuan ibu hamil dengan kebersihan gigi dan mulut (OHI-S) sebesar $r=-0.711$. Hal ini menunjukan bahwa terdapat hubungan yang kuat antara pengetahuan ibu hamil dengan kebersihan gigi dan mulut (OHI-S) selama masa kehamilan di Puskesmas Pandanwangi Kota Malang. Adanya hubungan yang kuat ini bisa disebabkan karena pengetahuan dapat membentuk perilaku sesuai dengan pengetahuan yang didapat. ${ }^{9}$

Hubungan antara sikap ibu hamil dengan kebersihan gigi dan mulut (OHI-S) selama masa kehamilan berdasarkan uji korelasi Rank Spearman, mempunyai nilai Signifikansi $=$ 0.000 kurang dari taraf signifikan $a=0.05$ yang menunjukkan bahwa $\mathrm{H}_{0}$ ditolak, sehingga hipotesis dalam penelitian ini dapat diterima. Koefisien korelasi hubungan antara sikap ibu hamil dengan kebersihan gigi dan mulut (OHIS) sebesar $r=-0.711$. Hal ini menunjukan bahwa terdapat hubungan yang kuat antara sikap ibu hamil dengan kebersihan gigi dan mulut (OHI-S) selama masa kehamilan di Puskesmas Pandanwangi Kota Malang. Sikap 
terbentuk terutama atas dasar kebutuhan yang kita miliki dan informasi yang kita terima mengenai hal tertentu. Dengan kata lain pengetahuan juga menentukan terbentuknya sikap seseorang. ${ }^{10}$

Hubungan antara tindakan ibu hamil dengan kebersihan gigi dan mulut (OHI-S) selama masa kehamilan berdasarkan uji korelasi Rank Spearman, mempunyai nilai Signifikansi $=$ 0.000 kurang dari taraf signifikan $a=0.05$ yang menunjukkan bahwa $\mathrm{H}_{0}$ ditolak, sehingga hipotesis dalam penelitian ini dapat diterima. Koefisien korelasi hubungan antara tindakan ibu hamil dengan kebersihan gigi dan mulut (OHI-S) sebesar $r=-0.711$. Hal ini menunjukan bahwa terdapat hubungan yang kuat antara tindakan ibu hamil dengan kebersihan gigi dan mulut (OHI-S) selama masa kehamilan di Puskesmas Pandanwangi Kota Malang. Praktik atau tindakan ini dibentuk oleh pengalaman interaksi individu dengan lingkungan, khususnya yang menyangkut pengetahuan dan sikapnya terhadap suatu objek. ${ }^{9}$

\section{KESIMPULAN}

Pengetahuan ibu hamil yang berkunjung ke Puskesmas Pandanwangi sebagian besar pada tingkat sedang $(60 \%)$, yaitu yang mempunyai skor total 20,33-29,67. Sikap ibu hamil yang berkunjung ke Puskesmas Pandanwangi sebagian besar adalah sedang (64\%), yaitu yang mempunyai skor total 20,33-29,67. Tindakan ibu hamil yang berkunjung ke Puskesmas Pandanwangi sebagian besar adalah sedang (68\%), yaitu yang mempunyai skor total 12-16. Sebagian besar ibu hamil yang berkunjung ke Puskesmas Pandanwangi mempunyai tingkat kebersihan gigi dan mulut (OHI-S) sedang (66\%) yaitu yang mempunyai skor total menurut Greene dan Vermillion: 1,33,0. Terdapat hubungan signifikan antara perilaku ibu hamil dengan kebersihan gigi dan mulut (OHI-S) selama masa kehamilan di Puskesmas Pandanwangi kota Malang. Masingmasing komponen perilaku yaitu pengetahuan dengan kebersihan gigi dan mulut (OHI-S) mempunyai nilai korelasi $r=-0.711$, sikap dengan kebersihan gigi dan mulut (OHI-S) mempunyai nilai korelasi $r=-0.707$ dan tindakan dengan kebersihan gigi dan mulut (OHI-S) mempunyai nilai korelasi $r=-0.525$.

\section{SARAN}

Perlunya dilakukan penelitian lanjutan yang berkaitan dengan faktor-faktor lain yang diduga dapat mempengaruhi kesehatan rongga mulut ibu hamil selama masa kehamilan. 


\section{DAFTAR PUSTAKA}

1. Al-Attas, SA. The Effect of SocioDemographic Factors on The Oral Health Knowledge, Attitude and Behavior in Female Population. Saudi Dental Journal. 2009: p.1-8.

2. Notoatmodjo, S. Promosi Kesehatan: teori dan aplikasi. Jakarta: Rineka Cipta; 2005.

3. Prawirodihardjo, S. IImu Kebidanan. Ed. 3. Jakarta: Yayasan Bina Pustaka; 2006.

4. Wijayanti, K. Asuhan Kebidanan pada Ibu Hamil. Universitas Tribhuwana Tunggadewi. 2007.

5. Habashneh, R. Factors Related to Utilization of Dental Services during Pregnancy. Journal of Clinical Periodontology. 2005; 32: p.815-21.
6. Axelsson, P. Diagnosis and Risk Prediction of Periodontal Disease. Quintessence Publishing Co. Kimberly Drive. 2002.

7. Budiarto, E. Biostatistika untuk Kedokteran dan Kesehatan Masyarakat. Jakarta: EGC. 2001.

8. Saryono. Metodologi Penelitian Kesehatan: Penuntun Praktis Bagi Pemula. Jogjakarta: Mitra Cendekia Press. 2008.

9. Istiarti, T. Menanti Buah Hati. Kaitan Antara Kemiskinan dan Kesehatan. Yogyakarta: Media Pressindo. 2000.

10. Mar'at, S., Kartono, LI. Perilaku Manusia. Pengantar Singkat Tentang Psikologi. Bandung: PT Refika Aditama. 2006. 